\title{
Francisco de Assis na Legenda Áurea de Jacopo de Varazze
}

\author{
Viviane Cunha \\ Universidade Federal de Minas Gerais \\ Eduardo Cursino de Faria Chagas \\ Universidade Federal de Minas Gerais
}

\section{Introdução}

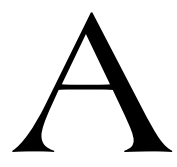

Legenda Aurea foi uma das principais obras dominicanas do século XIII, tendo o seu autor Jacopo de Varazze (1226?-1298) ou preparando sermões para outros clérigos. Membro da Ordem dos Dominicanos, fundada em Toulouse, no ano de 1216, por Domingos de Gusmão (1170-1221), a obra de Varazze revelou importantes aspectos do cristianismo, demonstrando como o pensamento escolástico e o cristianismo se relacionavam em textos de natureza distinta. Sua obra possui um caráter evangelizador, porém, com forte presença folclórica.

Entre os santos compilados na Legenda Áurea há um que se destaca, pela sua importância histórica, trata-se de São Francisco de Assis (1181 ou 1182-1226), fundador da Ordem dos Frades Menores, a qual desempenhou, na Idade Média, um importante papel, como instrumento evangelizador. Os princípios comuns das duas Ordens - Dominicana e Franciscana podem ser sintetizados em duas grandes metas: de atender às novas exigências espirituais surgidas na época, com o progresso urbano, uma vez que, em alguns locais, ou até mesmo, em algumas regiōes, a convivência entre pessoas de procedências diversas estimulava a indiferença religiosa. $\mathrm{O}$ outro objetivo era evitar o contato dessas pessoas com movimentos heréticos, e sobretudo, o combate à heresia em si mesma . 


\section{Desenvolvimento do Ocidente Medieval}

Nos séculos XII e XIII, a Europa passou por um período de grande desenvolvimento: expansão demográfica, com regióes onde o número de habitantes havia aumentado consideravelmente, como no norte e no centro da Itália, uma vez que dois dos fatores atuantes no aumento da mortalidade tiveram seu alcance reduzido: o recuo das epidemias, e o tipo de guerra que já não envolvia grandes tropas de combatentes anônimos. A guerra feudal passou a ser feita por pequenos bandos de guerreiros de elite. ${ }^{1} \mathrm{O}$ aumento da produtividade agrícola se modernizou, desde a substituição do boi pelo cavalo até o progresso dos pastos artificiais. Houve ainda, o surgimento de um novo meio intelectual, fundamentado na escolástica. A conseqüência desse progresso foi um grande movimento de urbanização, gerando, com isso, os grandes centros urbanos, onde se desenvolveu uma nova classe de homens, os burgueses, senhores do comércio, que conquistaram privilégios, sem contestar os fundamentos econômicos e políticos do sistema feudal. (LE GOFF, 1989)

De acordo com Jacques Le Goff, ${ }^{2}$ unido ao desenvolvimento urbano, "os Intelectuais" surgiram como trabalhadores especializados na ciência teológica ou jurídica. O termo intelectual é considerado por Jacques Le Goff como não pertencente ao século XIII, porém, serve para identificar os mestres que tinham como ofício "pensar e ensinar o seu pensamento", como homens de saber. O resultado disso tudo foi o crescimento das literaturas vernáculas, o nascimento das universidades e o desenvolvimento da filosofia escolástica.

Aliado a esse contexto apareceu um movimento herético, no sul da França, conhecido como catarismo, que preconizava dogmas divergentes do cristianismo. Um dos pontos de oposição entre os cátaros e a Igreja Romana era, justamente, o posicionamento anticlerical dos albigenses. Vale ressaltar aqui, que os termos albigenses e cátaros são equivalentes, o

\footnotetext{
${ }^{1}$ FRANCO JÚNIOR, 2001, p. 32-34.

${ }^{2}$ LE GOFF, 1989, p. 23.
} 
primeiro se referindo ao principal reduto dos cátaros, que era a cidade de Albi, situada ao norte de Toulouse, na França. Tendo em vista que o catarismo não se restringiu àquela cidade, os medievalistas preferem o termo cátaros/catarismo a albigenses/Albi. Com efeito, esse movimento se estendeu pela baixa Renânia, em algumas partes da França e do Império Romano-Germânico, e principalmente, na Provença e Itália do Norte. Durante certo tempo esse movimento ganhou muitos simpatizantes, o que foi para os cistercienses e o clero secular local uma derrota, aos quais o papado tinha confiado a ação da pregação. As conseqüências desse conflito entre os cátaros e a Igreja foram o abismo entre a França do Sul e as terras provençais, a instalação da Inquisição, e o surgimento das ordens mendicantes, com seu apelo popular aliado a uma grande erudição.

Diante dessas mudanças, a Igreja respondeu com a reforma gregoriana, um esforço de adaptação às mudanças que surgiram fora dela, e a resposta se deu com a fundação de novas ordens religiosas e um surto do movimento canônico. Foi de suma importância o combate do nicolaísmo, proibindo de vez o casamento e o concubinato às ordens religiosas, com isso a Igreja separou os seus clérigos dos leigos pela fronteira da sexualidade.

Assim como a escolástica forneceu à Igreja meios para lidar com as novas situações da sociedade, e as obras e coletâneas de exempla ajudaram os padres nas respostas para as novas necessidades espirituais dos fiéis, essa erudição também ajudou a separar a elite eclesiástica e os leigos, contribuindo com o crescimento da cultura folclórica e a aproximação das filosofias hereges, porém de linguagem mais popular. A Igreja sofreu uma forte derrota no fim do século XII, diante desses novos movimentos de leigos, dos quais o mais grave foi, sem dúvida, o do catarismo.

Dentro desse quadro, surge Domingos de Gusmão (1170-1221) responsável pela criação da Ordem dos Pregadores, que desde sua origem, procurou penetrar nas universidades, buscando munir-se de uma sólida bagagem intelectual, tendo em vista a finalidade definida por seu fundador: a luta contra a heresia. A iniciativa de Domingos compreendia a formação intelectual, para que os irmãos da Ordem estivessem preparados para combater as heresias, aliados a uma vida apostólica, disciplinada, e associada 
com a pobreza, em acordo com as novas exigências religiosas, surgidas com as transformações sociais acima citadas.

O envolvimento de Domingos de Gusmão na luta contra os hereges esteve na raiz da própria fundação de sua ordem, como um de seus principais objetivos. Nascido na região de Calaruega, Espanha, Domingos de Gusmão viveu em um período de lutas da Igreja contra os movimentos heréticos, e participou ativamente nas empreitadas, como a Cruzada Albigense. No norte da Itália, o movimento cátaro difundiu-se por várias cidades; o seu desenvolvimento nas cidades italianas ocorreu, também, por questões políticas, já que os Cátaros contaram com o apoio dos gibelinos, aliados ao Sacro Império Romano e contrários aos guelfos, favoráveis ao papado. Se, por um lado as transformações atingiam toda a Europa católica, seu epicentro, entretanto, estava de certa forma na Itália, região mais povoada, urbanizada e uma das mais heréticas do Ocidente.

\section{A Legenda Áurea e seu autor}

Dentro desse cenário, anos mais tarde, um homem entrou para a ordem dos Dominicanos: Jacopo de Varazze, responsável pela criação de uma das mais importantes obras hagiográficas, composta na segunda metade do século XIII. Jacopo nasceu na cidade de Varazze, próxima a Gênova, mas, não é precisa a data de seu nascimento, situando-se entre 1226 e 1230. Jacopo, aos dezoito anos, ingressou na Ordem dos Dominicanos, no mesmo ano que Tomás de Aquino, em cuja hierarquia progrediu, por sua cultura e dedicação religiosa, tornando-se, a partir de 1267, o líder da Ordem, na província da Lombardia, cargo que ocupou por vinte anos. Em 1292, foi nomeado arcebispo de Gênova, pelo papa Nicolau IV. Nesse cargo teve, em 1295, papel decisivo, na reconciliação entre genoveses gibelinos (adeptos do imperador) e guelfos (adeptos do papa). Morreu em 1298, tornando-se, em 1645, patrono de Varazze, sendo beatificado em 1816, pelo papa Pio VII.

Autor de muitos sermões e de uma Crônica de Gênova, escrita em 1293, sua grande obra foi a Legenda Áurea, um conjunto de textos de 
grande valor moral e pedagógico (por isso, Áurea 'de ouro'). Entende-se, literalmente, por Legenda "aquilo que deve ser lido", possuindo também, o sentido de "leitura da vida de santos". O objetivo imediato de Jacopo de Varazze foi fornecer aos seus colegas de hábito, os frades pregadores, material para a elaboração de seus sermões. Material teologicamente correto, isento de heresias, mas também compreensível e de leitura agradável aos leigos que ouviam a pregação. Para tanto, Jacopo, naturalmente, utilizou o vasto material, de diversas proveniências temporais e espaciais, desde textos litúrgicos, bíblicos e historiográficos, cristãos e não cristãos, que se estendem da antiguidade tardia ao século XIII.

Os seguidores de Domingos de Gusmão (1170-1221) e de Francisco de Assis (1182-1226) atuavam no meio do povo, ao contrário dos monges tradicionais, enclausurados na segurança de seus mosteiros. Os Dominicanos, assim como os Frades Menores, foram importantes expoentes, durante a intensa pregação e repressão aos hereges, e souberam lidar melhor do que as antigas ordens monásticas, com as novas necessidades sociais e espirituais. Nesse contato cotidiano, os mendicantes recorriam mais às línguas vulgares que ao latim, não que com isso lhes faltasse a erudição, pois, na maior parte das nascentes universidades do século XIII, havia grandes teólogos franciscanos e dominicanos, portanto, o trabalho contra a heresia dos cátaros foi mais efetivo, no uso do contato direto com a população, valendo-se de mensagens simples e objetivas, aliadas à erudição.

Para que essa pregação pudesse ser bem eficiente, passou-se a recorrer ao exemplum, ${ }^{3}$ relato breve, dado como verídico, e destinado a ser inserido em um discurso, ou sermão, para convencer os ouvintes, através de uma lição moralizante. Esse tipo de narrativa, existente desde a Antigüidade as Fábulas, por exemplo -, ganhara uma nova roupagem, e desenvolveuse nos meios monásticos, para, em seguida, alastrar-se largamente, nos ambientes urbanos, locais onde os interesses econômicos e a convivência de pessoas de diversas procedências estimulavam a contestação, ou mesmo, a indiferença religiosa. E nisso residia a importante função do exemplum

${ }^{3}$ VARAZZE, 2003, p.13. 
como instrumento de persuasão, que tirava sua lição da descrição de um comportamento negativo, gerando conseqüências nefastas para seu protagonista. O material era obtido através, tanto da oralidade, como de fontes eruditas.

\section{O sucesso da Legenda Áurea}

A história da Igreja e suas alterações estratégicas em resposta ao novo cenário europeu foram feitas de avanços e recuos. A Igreja somente tornouse bem-sucedida porque se paganizou, tema que passou a ser recorrente nas obras eclesiásticas, expondo a consciência que tiveram os religiosos das pressóes sobre o cristianismo, na proporção em que o campo passou a trazer suas concepções para o Imaginário cristão. Assim, nesse novo ambiente, houve um crescimento da devoção aos santos. Das estratégias utilizadas pelo cristianismo na evangelização dos povos, a Hagiografia tornou-se um dos principais veículos de testemunho da fé e dos milagres. Nesse ponto, estava a grande realização da Legenda Áurea, pois o sucesso dessa obra confundiuse com o próprio sucesso do culto dos santos. A sua grande recepção começou de imediato pela Itália, e, logo a seguir, em quase toda parte, e graças a uma mensagem simples a Legenda Aurea transmitiu de forma nítida e firme a essência do cristianismo da época. De forma satisfatória, o texto havia encontrado um ponto de intercessão entre a elite cultural e o vulgo, mesmo sendo interpretados de forma diferente, pelos dois pólos culturais. Na Legenda de Jacopo isso foi possível graças ao registro erudito de elementos folclóricos nas narrativas dos exempla. Ao selecionar o material erudito e popular, Jacopo de Varazze oscilou entre construir um discurso firmemente ortodoxo e admitir a influência de antigas heranças culturais. $\mathrm{O}$ texto evangelizador ficava, em diversas passagens, contaminado pela presença da mitologia, como, por exemplo, na narrativa sobre São Cristóvão (capítulo 95), em que esse santo aparece carregando "o mundo em seus ombros", assim como o gigante Atlas na mitologia greco-romana. ${ }^{4}$

${ }^{4}$ VARAZZE, 2003, p.573. 
Como decorrência do reconhecimento deste equilíbrio entre as diferentes camadas da espiritualidade, através de um texto simples, mas não menos erudito, a Legenda Aurea conheceu enorme sucesso na Idade Média.

Outra característica importante da Legenda Aurea é a respeito de sua divisão, que está organizada de acordo com o calendário litúrgico. Este calendário possui quatro tempos e suas respectivas datas de festividades: Desvio (Adão e Eva se afastam de Deus), Renovação (iniciado por Moisés até o nascimento de Cristo), Reconciliação (através de Cristo) e Peregrinação (vida presente, tempo de mudança); ${ }^{5}$ os tempos se sucedem de acordo com a relação de proximidade e distanciamento de Deus. No prólogo, observase a troca do tempo do desvio pelo da renovação, é nítida a idéia de remissão e afastamento do pecado original, inclusive, por esta troca da ordem dos tempos:

Embora o desvio tenha precedido a renovação, a Igreja prefere começar todos os seus ofícios no tempo da renovação, não do desvio, isto é, no Advento do e não na Septuagésima, por dois motivos. O primeiro, para não parecer começar no tempo do erro, o segundo, porque com o Advento de Cristo tudo foi renovado. ${ }^{6}$

Distribuídos dentro dos quatro tempos há onze relatos dedicados a Cristo e a Maria, cujos títulos revelam temas como: nascimento, purificação, remissão dos pecados e a morte libertadora, que foram dispostos da seguinte maneira: O Advento do Senhor, A Natividade de Nosso Senhor Jesus Cristo Segundo A Carne, A Circuncisão do Senhor, A Epifania do Senhor, A Purificação da Bem-Aventurada Virgem Maria, A Anunciação do Senhor, A Paixão do Senhor, A Ressurreição do Senhor, A Ascensão do Senhor, A Assunção da Bem Aventurada Virgem Maria, A Natividade da Bem-Aventurada Virgem Maria. Cada um desses capítulos possui uma data no calendário, com sua respectiva festa, ${ }^{7}$ assim como todos

\footnotetext{
${ }^{5}$ VARAZZE, 2003, p.41.

${ }^{6}$ VARAZZE, 2003, p.42.

7 VARAZZE, 2003, p.31-36.
} 
os santos biografados. São Francisco de Assis foi registrado dentro das festas do tempo da peregrinação, e sua data de festividade está localizada no mês de outubro, dia quatro.

\section{São Francisco de Assis na Legenda Áurea}

Dentre os santos biografados na obra de Jacopo de Varazze, dois serão objetos de análise neste pequeno estudo, Domingos de Gusmão e Francisco de Assis, santos que atuaram no sentido de abrir para os homens novos caminhos de salvação. Em algumas passagens eles são apresentados como companheiros. No capítulo dedicado a Domingos, Jacopo relata como foi o primeiro encontro entre os dois santos: um frade menor narra aos irmãos da Ordem dos Pregadores a visita de Domingos a Roma, para a confirmação de sua Ordem junto ao Papa. Segundo a narrativa, o dominicano teria visto, durante a sua oração, Cristo nos ares, com três lanças, prestes a destruir o mundo. A Virgem Maria apareceu rapidamente e perguntou a seu Filho o que pretendia fazer. Cristo revelou sua intenção a Ela, que então ajoelhou-se diante Dele e pediu-Lhe para ter piedade, que esperasse um pouco mais, e que temperasse a Sua justiça, pois havia dois servos de Deus que iriam percorrer o mundo levando o seu Santo Nome. Assim, Maria mostrou ao seu Filho irado os dois homens que lutariam em seu nome. Primeiro foi apresentado Domingos e depois Francisco, e, a partir desse momento, Jesus se acalmou. Foi durante essa visão, que Domingos veio a conhecer Francisco, e, quando o viu, no dia seguinte, na igreja, reconheceu$\mathrm{o}$, sem que o apontassem, abraçou-o e deu-lhe santos beijos, contou-lhe sobre o sonho, disse-lhe que juntos trilhariam o caminho de Deus e que nenhum adversário os derrotaria. ${ }^{8}$

A união desses dois importantes santos do século XIII, na luta contra a heresia, fora uma mensagem forte, tanto para os iletrados, quanto para os letrados da época, e uma boa demonstração do exemplum, como forma

${ }^{8}$ VARAZZE, 2003, p.618. 
de desviar o fiel da heresia cátara. A respeito da situação política referida, sobre os gibelinos apoiarem os cátaros, há uma passagem no capítulo dedicado a Francisco, que também se encontra na Legenda Maior, de São Boaventura. Francisco e seu amigo Frei Silvestre estavam de passagem pela cidade de Arezzo, uma das envolvidas na guerra civil mencionada, quando o servo de Deus viu, no ar das redondezas, demônios que se alegravam com a guerra, e chamando seu companheiro Silvestre disse-lhe: "Vá à porta da cidade, e da parte de Deus onipotente ordene aos demônios que saiam de lá". Silvestre foi rapidamente até a porta, onde gritou com força: "Da parte de Deus e por ordem de nosso pai Francisco, saiam todos, demônios". Pouco tempo depois a paz foi restabelecida entre os cidadãos. ${ }^{9}$ Essa cidade toscana era uma das que formavam a liga aliada aos gibelinos, simpatizantes dos os cátaros. Percebe-se, novamente, a intenção do dominicano Jacopo de combater a heresia cátara, ao associar os demônios à presença albigense na cidade. Esse relato serviu, muito bem, ao propósito da filosofia dos frades pregadores, no combate à heresia. Destaca-se ainda, nesse relato, a presença mítica da concepção medieval de que os demônios não habitavam nem o céu, pois haviam sido expulsos; e nem a terra, lar dos seres corpóreos, portanto eles habitavam os ares. ${ }^{10}$ Essa concepção está registrada no capítulo dedicado a São Matias. ${ }^{11}$

Sobre a vida de Francisco de Assis, Jacopo selecionou passagens das hagiografias de Tomás de Celano, São Boaventura e do Frei Hugolino de Montegiorgio, mas não se limitou a compilá-las, apenas selecionou passagens que melhor convinham, com o objetivo principal, moral e pedagógico, de ser compreensível e agradável aos leigos, que ouviriam a pregação. No capítulo 144, São Francisco é apresentado ao leitor, como todos os santos da Legenda Aurea, através de uma análise etimológica de seu nome, e, assim como 57\% dos capítulos dedicados aos santos, não havia intenção de ser

\footnotetext{
9 VARAZZE, 2003, p.839-840.

${ }^{10}$ VARAZZE, 2003, p.277.

${ }^{11}$ VARAZZE, 2003, p.277.
} 
um estudo lingüístico, e sim, uma intenção de explicar a santidade. Para Jacopo de Varazze, a busca do sentido verdadeiro do nome não estava no sentido externo dele, mas naquilo que revelou o destino do santo anunciado por seu nome. ${ }^{12}$

No capítulo sobre Francisco de Assis, primeiramente chamado de João - depois mudou de nome e passou a ser conhecido como Francisco - são mostradas sete causas para a mudança. ${ }^{13}$ A primeira é pelo fato de ter ele recebido o dom de Deus de falar a língua francesa, quando estava tomado pelo Espírito Santo. A segunda causa é que devido a esse nome singular, sua crença ganharia conhecimento mais rapidamente. A terceira causa é que ele e os seus seguidores deveriam transformar muitos servos do demônio em seres livres e francos. A quarta causa é por demonstrar a ferocidade de um coração franco, por natureza, um espírito de verdade. As três últimas causas Jacopo afirma que estão associadas às franciscas, do latim fascem, que chega ao português como feixe, o sentido próprio da palavra.

O plural da palavra em latim fasces representava um feixe de varas, envolta no qual estava uma machadinha, que os litores (oficiais que atuavam como "abre alas" para os cônsules) levavam à frente dos primeiros magistrados, como símbolo de poder de vida e morte. Passou, então, a ser símbolo do poder consular de Roma. ${ }^{14}$ Quando e por que o nome Francisco substituiu o de João Batista, o santo da pregação, por quem Francisco teve uma predileção, não se sabe. Das três hipóteses levantadas por Jacques Le Goff a mais verossímil diz respeito a um apelido a um apelido que the teria sido dado na juventude devido a sua paixão pela língua francesa. ${ }^{15}$ Tomás de Celano registrou que quando Francisco de Assis estava possuído pela graça do Espírito Santo, ele falava em francês, Jacopo também relatou tal fato, conforme foi dito acima.

12 VARAZZE, 2003, p. 17-18.

13 VARAZZE, 2003, p. 836.

${ }^{14}$ FARIA, 1956, p. 389.

${ }^{15}$ LE GOFF, 2005, p. 58-59. 
No decorrer da narrativa sobre Francisco, exemplos de falsa conduta e suas implicações são expostos em forma de pequenos contos, no típico formato do já citado gênero literário conhecido por exemplum. Como modelo disso há a narrativa do irmão que todos julgavam santo, mas que era, na verdade, um falso. Essa narrativa tinha ainda outro objetivo, característico da ordem dos dominicanos, que era a pregação das doutrinas cristãs. Influenciada por Pedro Abelardo, Santo Anselmo e Guillaume de Champeaux uma nova doutrina de confissão dos pecados, que buscava as fontes na consciência, alimentou a nova prática de confissão auricular individual, em detrimento da antiga confissão pública. Essa mudança foi sancionada no quarto concílio de Latrão, tornando-se obrigatório o ato de confessar-se pelo menos uma vez por ano. ${ }^{16} \mathrm{Na}$ passagem que se segue houve o registro da conseqüência do comportamento contrário à regra: a descrição do irmão que, externamente, parecia de eminente santidade, observava a regra do silêncio, com tal rigor, que só se comunicava por sinais, e não de viva voz, sendo por isso louvado, por todos, como santo. Suspeitoso, Francisco disse: "Meus irmãos, parem de louvar nele ilusões diabólicas, aconselhem-no a se confessar uma vez ou duas vezes por semana. Se não o fizer, há nisso tentação do diabo e ilusão fraudulenta". ${ }^{17}$ Quando os irmãos comunicaram isso ao falso irmão, o mesmo pôs um dedo sobre a boca e, sacudindo a cabeça, fez sinal de que não se confessaria. Dias depois, acabou sua vida entre vômitos e atos pecaminosos. Nesse relato, o ouvinte teve contato com o exemplum, como instrumento de persuasão, para levar o crente a seguir as regras da Igreja, e se confessar, conforme ditavam as regras.

Milagres ocorridos depois da morte de Francisco também foram usados como exemplos de boa conduta. Certa vez, um homem honrado, chamado Rogério, entrou em uma igreja em que havia um quadro de Francisco, e começou a cogitar se seria verdadeiro ter sido Francisco honrado com o milagre dos estigmas, ou se tudo teria sido uma ilusão, ou mesmo, uma simulação intencional de seus irmãos. Enquanto pensava

${ }^{16}$ LE GOFF, 2005, p.31-32.

17 VARAZZE, 2003, p. 838. 
nisso, ouviu, de repente, um ruído semelhante ao de um dardo lançado por uma balista e sentiu-se gravemente ferido na mão esquerda, mas apesar de não haver nenhum rasgo em sua luva, ao tirá-la descobriu, na palma da mão, uma profunda ferida, como se tivesse sido feita por uma flecha. A mão ardia tanto que Rogério parecia que iria desmaiar de dor. Ele se arrependeu, e testemunhou acreditar na realidade dos estigmas do bem-aventurado Francisco. Dois dias depois, tendo orado ao santo de Deus por seus estigmas, ficou imediatamente curado. ${ }^{18}$ Essa história edificante mostra para o fiel, através de um relato real, como é perigoso duvidar da santidade de Deus. Em honra de seus santos Deus intercede e pune os incrédulos, blasfemos e hereges. Fato semelhante de incredulidade foi registrado no relato do cavaleiro insano:

Um cavaleiro que zombava das obras de Francisco e de seus milagres, certo dia estava jogando dados quando, cheio de loucura, disse aos assistentes: "Se Francisco é santo, que venha um lance de 18". E imediatamente os três dados caíram no número seis, e isso em nove lances seguidos. Contudo cada vez mais insensato, ele disse: "Se é verdade que Francisco é santo, que hoje meu corpo caia varado por uma espada, se não é santo, que eu saia incólume”. Quando o jogo acabou, para agravar a prece, insultou seu sobrinho, que enfiou uma espada nas vísceras do tio e o matou no mesmo instante. ${ }^{19}$

Destaca-se ainda o relato dos frades de Vicera, que pediram a um homem a sua carroça emprestada e como resposta ele disse: "Eu prefiro esfolar dois de vocês junto com São Francisco do que emprestar minha carroça". Pouco tempo depois o filho do homem adoeceu e logo em seguida morreu. Quando viu o filho morto, o homem chorou muito, e evocou Francisco, pediu-lhe perdão pela sua blasfêmia e implorou devotamente que devolvesse seu filho. Logo em seguida, o filho ressuscitou e relatou ao

\footnotetext{
18 VARAZZE, 2003, p. 841-842.

19 VARAZZE, 2003, p. 847.
} 
pai que São Francisco o levou até um pomar muito belo e lhe disse: "Volta para seu pai, não quero retê-lo mais". ${ }^{20}$ A punição para a incredulidade é bastante recorrente em toda a Legenda Aurea, e mesmo em outras obras hagiográficas, incluindo-se aí os textos marianos.

Se, em algumas narrativas os que foram incrédulos tiveram o merecido castigo, em outras, se destacam o resultado da devoção ao santo: havia uma mãe, devota de São Francisco, que caiu em profunda tristeza, pois havia perdido sua única filha. $\mathrm{O}$ santo lhe apareceu e lhe disse para não chorar mais, pois sua filha lhe seria devolvida. A mãe recuperou a confiança e, ao lado do corpo da filha, invocou o nome de São Francisco, não deixou que a levassem para ser enterrada, e algum tempo depois, a filha se levantou, em plena saúde. ${ }^{21}$ Outro relato de milagre, parecido com esse último, se deu na cidade de Sezza, quando ao desabar uma casa, um jovem foi esmagado. Ele já estava no caixão, quando a mãe invocou, com toda a sua devoção, o bem-aventurado Francisco, e, por volta da meia noite, seu filho acordou, e se levantou, completamente curado. ${ }^{22}$ Encontra-se, nas passagens relatadas, a recompensa para a fidelidade a Deus e aos seus santos. Em outros capítulos da Legenda Aurea, isso é um lugar comum, os santos mártires encontraram seu devido galardão, no paraíso.

A temática da correta conduta do fiel em relação à confissão, bem expresso no relato do falso santo, ocorre em outra passagem: uma mulher foi devota de Francisco durante toda a sua vida, e quando veio a falecer, no momento de seu funeral, repentinamente, ela se ergueu do caixão, chamou um dos sacerdotes presentes, e disse-lhe que estava condenada a permanecer em uma dura prisão, pois morreu sem confessar um pecado que fosse. Então Francisco orou por ela e Deus concedeu a ela voltar a seu corpo para se confessar. ${ }^{23}$

\footnotetext{
${ }^{20}$ VARAZZE, 2003, p. 847.

${ }^{21}$ VARAZZE, 2003, p.848.

${ }^{22}$ VARAZZE, 2003, p. 848.

${ }^{23}$ VARAZZE, 2003, p. 846-847.
} 
As opçōes dos fiéis eram bem claras nas narrativas dos milagres de Francisco, e em outras biografias de santos registradas na Legenda Aurea: a escolha inevitável que cada ser humano deveria fazer, posicionando-se ao lado dos santos ou dos demônios.

\section{Conclusão}

Como dominicano e, portanto, um homem de saber, Jacopo de Varazze levou a quase toda a Europa, de forma direta ou através de copistas, a sua visão do cristianismo, traduzindo a ideologia maniqueísta da época, servindo-se ora dos textos da Sagrada Escritura, ora de relatos fantásticos, mostrando o dualismo do homem medieval: Deus/Demônio, Bem/Mal, Céu/Inferno e outras tantas dicotomias. Cerca de mil manuscritos latinos da Legenda Aurea chegaram até nós, juntamente com as incontáveis versōes da obra, para quase todas as línguas vernáculas ocidentais, produzidas desde a Idade Média, com o único objetivo de propagar a fé cristã e combater a heresia, principalmente, a cátara. A hagiografia não deixa de ser, portanto, um recurso retórico de função eclesiástica, um importante instrumento de transmissão de ensinamentos, que podem atuar na conduta dos devotos. O enfoque da biografia de Francisco de Assis e seu uso na Legenda Áurea, nos dá uma idéia, ainda que singela, de como os exempla eram eficazes para combater as heresias, e ao mesmo tempo, para determinar maneiras de conduta do homem medieval. 


\section{Referências Bibliográficas}

FARIA, Ernesto. Dicionário Escolar Latino-Português. Porto: Porto, 1956.

FRANCO JÚNIOR, Hilário. A Idade Média, nascimento do ocidente. $2^{\circ} \mathrm{ed}$. São Paulo: Brasiliense, 2001.

JACOPO DE VARAZZE. Legenda Aurea: Vidas de Santos. São Paulo: Companhia das Letras, 2003.

LE GOFF, Jacques. Os Intelectuais na Idade Média. São Paulo: Brasiliense, 1989.

LE GOFF, Jacques. São Francisco de Assis. $7^{\circ}$ ed. Rio de Janeiro: Record, 2005 .

LE GOFF, Jacques. O Apogeu da Idade Média. São Paulo: Martins Fontes, 1992.

SOUZA, Néri de Almeida. "Palavra de púlpito e erudição no século XIII. A Legenda Aurea de Jacopo de Varazze”. Revista Brasileira de História, São Paulo, v. 22, n. 43, 2002, p. 67-84. 


\section{Resumo}

O objetivo deste artigo é propor uma análise da presença de São Francisco de Assis na Legenda Aurea e os recursos intelectuais de seu autor, Jacopo de Varazze, quase sempre utilizados com o fim de evangelizar e responder às novas necessidades espirituais dos séculos XII e XIII, nos sermões dos dominicanos. Para tanto será discutido o contexto histórico desse período como grande responsável, não apenas pela formação do clérigo Jacopo de Varazze e sua obra, mas também pelo surgimento das ordens mendicantes e seus idealizadores.

\section{Abstract}

The purpose of this article is to propose an analysis about the presence of Saint Francis of Assisi in the Golden Legend and the intelectual prowess of its author, Jacopo de Varazze, often used in order to evangelize and meet the spiritual needs of the Twelfth and Thirteenth Centuries, in the sermons of the domicians. To do so will discuss the historical context of this period as largely responsible, not only for the formation of Jacopo de Varazze and his work, but also by the emergence of the mendicant orders and their creators. 